\title{
Does angioplasty need on site surgical cover? A physician's view
}

\author{
T R D Shaw
}

In Europe, including the United Kingdom, many cardiac laboratories perform coronary angioplasty without having on site facilities for surgery. They use a rapidly accessible surgical unit nearby for back up in the event of occlusion. This system was developed as a pragmatic response to balloon dilatation-a revolutionary change in the treatment of coronary disease that was based on angiography skills and facilities. It seemed a reasonable arrangement because Gruentzig and the pioneers of angioplasty had indicated that back up surgery should be provided within 90-120 minutes.

The justification for continuing angioplasty with nearby off site surgery is the results obtained. Richardson et al reported that in Belfast the unit with off site surgery provided revascularisation for patients slightly sooner than the unit with on site surgery. ${ }^{1}$ None of the 12 patients who had off site surgery died. At the Western General Hospital in Edinburgh our operating theatre for cardiac surgery is three miles away from the catheterisation laboratory. ${ }^{2}$ Of 407 angioplasties carried out up to 1989 , seven patients had emergency coronary surgery. One, with a main stem dissection, died after operation. Of the six others, three have good left ventricular function and three have moderate function. All are in New York Heart Association symptom class I or II after surgery. The angioplasty mortality was $0.25 \%$. These results are similar to those of centres with on site surgery. ${ }^{3-6}$ In Belfast and in Edinburgh travel in an ambulance, which had resuscitation facilities, did not seem to cause any clinical deterioration.

In 1988 two sets of guidelines for carrying out coronary angioplasty were published. ${ }^{78}$ Both strongly emphasised on site surgery but neither indicated the time limit for surgical back up. I suggest that we should consider a recommended time limit, perhaps of $120 \mathrm{~min}$ utes, between final occlusion and revascularisation. Such a limit, irrespective of whether the surgery is on site or off site, would help to maintain good standards in coordinating the scheduling of angioplasty cases with the surgical list and in limiting the time spent on attempts to reopen the occluded artery, and in the surgical unit getting the patient speedily through to reperfusion. More data on survival and myocardial preservation are needed to define an appropriate time limit more pre- cisely. Although a small series reported by Reul et al suggested that infarction could be avoided when operation was performed within 25 minutes of the onset of ischaemia, ${ }^{9}$ infarction rates of $27 \%$ and $44 \%{ }^{10}$ were found in large angioplasty centres where patients could be transferred directly to an operating theatre. O'Kane et al reported no deaths in 25 patients operated on at a mean of 285 minutes after occlusion. ${ }^{11}$

For most angioplasties the selection of cases is similar whether surgical back up is on site or off site. For both, the cardiologist and surgeon must judge that the patient has ventricular function and a coronary anatomy that will in the event of occlusion allow a viable circulation until cardiopulmonary bypass has been started. For very high risk angioplasty, in which occlusion might cause extensive myocardial impairment an aortic balloon pump or a femoral-femoral bypass support system is needed. The numbers of high risk patients treated by angioplasty are growing and such patients should only be treated with off site surgical back up if suitable transport with portable support systems is available and shown to be effective. This proviso also applies when the operating theatre is on site but remote from the cardiac laboratory. The need for surgical back up has been declining. ${ }^{12}$ Although occlusion develops in $5 \%$ of patients treated by angioplasty our ability to reopen vessels has improved and only $3 \%$ need surgical back up while $97 \%$ do not. The use of stents, perfusion catheter/balloons, and other devices is likely to reduce the need further.

I believe therefore that it is reasonable for experienced cardiac laboratory teams to perform coronary angioplasty using nearby off site operating theatres if back up can be obtained within an appropriate time limit.

There are, however, difficult choices to be made about the plans for future facilities. There is much to be said in favour of combining invasive cardiology and cardiac surgery. Interventional cardiology will increase considerably and the choice of treatment will need closer medical and surgical discussion. Back up will be needed for various forms of non-surgical treatment. But should cardiology centralise or cardiac surgery decentralise? Should diagnostic angiography be separated from interventional cardiology? The management of recent onset and unstable angina 
may require much closer links between coronary care units and cardiac $x$ ray suites but it is difficult to separate such admissions to coronary care units from general medical admissions and to send them direct to off site regional cardiac centres. Currently I think that coronary angioplasty with off site surgical back up makes the best use of the facilities we have.

1 Richardson SG, Morton P, Murtagh JG, O'Keefe DB, Murphy P, Scott ME. Management of acute coronary occlusion during percutaneous transluminal coronary angioplasty: experience of complications in a hospital without on site facilities for cardiac surgery. $\mathrm{Br} \mathrm{Med} J$ 1990;300:355-8.

2 Shaw TRD, Starkey IR, Essop AR, et al. Emergency coronary bypass surgery after vessel occlusion at angioplasty in centres without on-site cardiac surgery plasty in centres without on-site

3 Barner HB, Lea JW, Naunheim KS, Stoney WS. Emergency coronary bypass not associated with preoperative shock in failed angioplasty, after thrombolysis and for acute myocardial infarction. Circulation 1989; 79 (suppl I):152-9.
4 Golding LAR, Loop FD, Hollman JL, et al. Early results of emergency surgery after coronary angioplasty. Circulation 1986;74(suppl III):26-9.

5 Parsonnet V, Gielchinsy I, Hochberg MS, et al. Emergency surgery after failed ang

6 Talley JD, Weintraub WS, Anderson HV, et al. Late clinical outcome of coronary bypass surgery after failed angiooutcom or coronary bulation 1987;76 (suppl IV):352.

7 ACC/AHA Task Force Report. Guidelines for percutaneous transluminal coronary angioplasty. J Am Coll Cardiol transluminal cord

8 Bourassa MG, Alderman EL, Bertrand M, et al. Report of the Joint International Society and Federation of Cardiology/World Health Organisation Task Force on Coronary Angioplasty. Eur Heart J 1988;9:1034-45.

9 Reul GJ, Cooley DA, Hallman GL, et al. Coronary artery bypass for unsuccessful percutaneous transluminal coronary angioplasty. J Thorac Cardiovasc Surg 1984;88: 685-94.

10 Killen DA, Hamaker WR, Reed WA. Coronary artery bypass following percutaneous transluminal coronary angioplasty. Ann Thorac Surg 1985;40:133-8.

11 O'Kane H, Cleland J, Gladstone D, Galvin I, Buckels J. Emergency operation after failed percutaneous angioplasty: how late? Br Heart J 1989;61:93-4.

12 Detre K, Holubkov R, Kelsey S, et al. Percutaneous transluminal coronary angioplasty in 1985-1986 and 1977-1981: The National Heart, Lung and Blood Registry. N Engl J Med 1988;318:265-70.

\section{VIEWS FROM THE PAST Ernest Henry Starling}

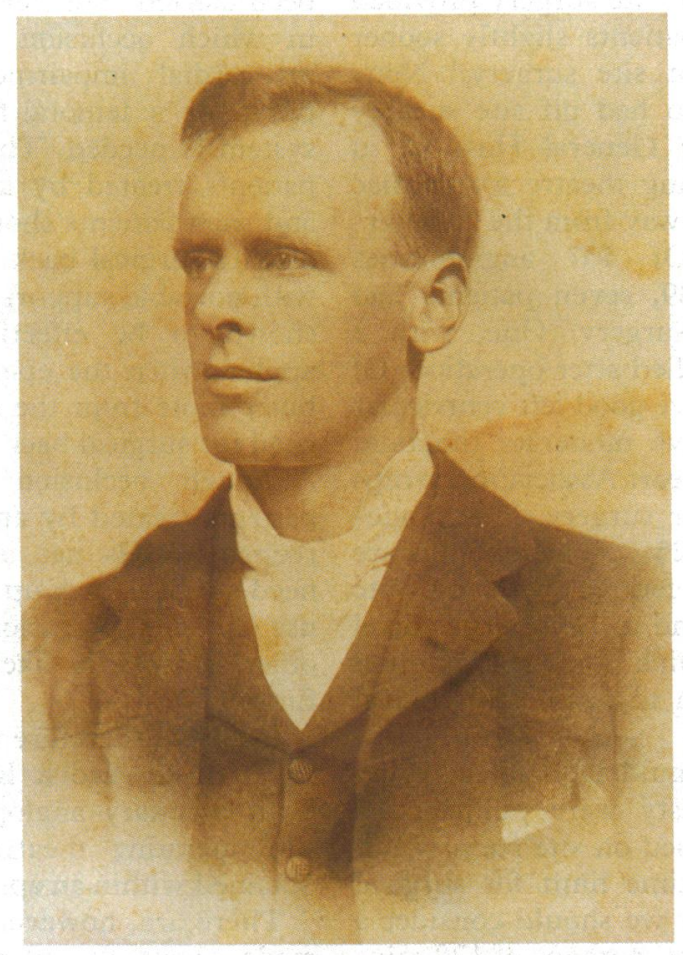

To cardiologists, Starling is best known for his law of the heart, which indicated that cardiac output is determined by diastolic fibre length. Here we see him as a young man at the threshold of his career. In 1899, at the age of 33, he succeeded Sharpey-Schafer as Jodrell professor of physiology at University College, London (Lewis collection).

DENNIS M KRIKLER 